\title{
Loss-Averse Retailer's Optimal Ordering Policies for Perishable Products with Customer Returns
}

\author{
Xu Chen and Qian Zhou \\ School of Management and Economics, University of Electronic Science and Technology of China, Chengdu 611731, China \\ Correspondence should be addressed to Xu Chen; xchenxchen@263.net
}

Received 1 August 2014; Revised 26 September 2014; Accepted 1 October 2014; Published 15 October 2014

Academic Editor: Zhong-Ke Gao

Copyright (C) 2014 X. Chen and Q. Zhou. This is an open access article distributed under the Creative Commons Attribution License, which permits unrestricted use, distribution, and reproduction in any medium, provided the original work is properly cited.

\begin{abstract}
We investigate the loss-averse retailer's ordering policies for perishable product with customer returns. With the introduction of the segmental loss utility function, we depict the retailer's loss aversion decision bias and establish the loss-averse retailer's ordering policy model. We derive that the loss-averse retailer's optimal order quantity with customer returns exists and is unique. By comparison, we obtain that both the risk-neutral and the loss-averse retailer's optimal order quantities depend on the inventory holding cost and the marginal shortage cost. Through the sensitivity analysis, we also discuss the effect of loss-averse coefficient and the ratio of return on the loss-averse retailer's optimal order quantity with customer returns.
\end{abstract}

\section{Introduction}

Customer returns (returns of product from customers to retailers) are very common in the retail industry. For example, Wal-Mart provides full credit for customer returns under very broad circumstances. At the same time, customer returns are costly and problematic, especially for the perishable products. Due to increasing competition, hastened technological advancement, and rapidly changing market environments, perishable products are becoming more and more desirable $[1,2]$. So, customer returns have been a challenge of supply chain management.

On the other hand, with a better understanding of peoples' own behavior, not only the assumption of rational man, which was the fundamental assumption of the economics, was questioned and criticized, but also the risk neutral assumption that often sets in the supply chain management has gradually been replaced by other decision-making properties. For example, some decision makers may belong to the risk aversion while some belong to the risk seeker [3]. As to the loss aversion, it may be the characteristic that belongs to all the decision makers $[4,5]$. It has been proved by many experimental studies that risk attitude plays an important role in the supply chain members' decision makings $[6,7]$. So, it is important to study the loss-averse retailer's optimal ordering policies for perishable product with customer returns.

Two streams of research are relevant to the work in this paper. The first is research on customer returns. Chen and Bell [8] address the simultaneous determination of price and inventory replenishment when customers return product to the firm and discuss the impact of customer returns on pricing and order decisions. Chen and Bell [9] further investigate a decentralized supply chain with customer returns and price dependent stochastic demand; they propose an agreement that includes two buyback prices to coordinate the supply chain. The other relevant literature is research on the ordering policies for perishable product considering the loss-aversion decision bias. Loss aversion is a basic view of the prospect theory of Kahneman and Tversky [10]. Loss aversion points that the sensitivities of the gains and losses are different, and the sensitivity of losses is higher. Schweitzer and Cachon [11] first studies the newsboy model of loss aversion. They found that, without considering the shortage cost, the newsboy of loss aversion has a less optimal order quantity than the newsboy of risk neutral under the same circumstances and, with the deepening of his loss aversion, the optimal order quantity will be less. Wang and Webster [12] expand the basic model of Schweitzer and Cachon [11] by taking the shortage 
cost into account. They also had sensitivity analysis to the parameters of the model and gain that if the shortage cost is small, the optimal order quantity for the newsboy of loss aversion is more than that for the newsboy of risk neutral; the optimal order quantity of the loss aversion newsboy model is increasing with wholesale price and decreasing with retail price, all of which features do not exist in the traditional risk neutral newsboy model. Recently, Chen et al. [3] consider a one-period two-echelon supply chain which consisted of a loss-averse retailer and a risk-neutral supplier and derive that the loss-averse retailer may order less than, equal to, or more than the risk-neutral retailer. In addition, they study the supply chain coordination and show that there always exists a Pareto contract compared with noncoordinating contracts. Li et al. [13] investigate a two-echelon supply chain composed of a risk-averse manufacturer and a risk-averse retailer under demand uncertainty in two different supply chain structures. They use the constant absolute risk aversion (CARA) function and game theory to build the models and analyze the effects of risk aversion on the supply chain's optimal price and quality decisions.

Although there are so many related papers about perishable product ordering policy with customer returns or with loss aversion, it still lacks for the integrated consideration by combining two of them together. Therefore, taking the customer returns and loss aversion into account in the research of the perishable products ordering policy can not only fill the gaps, but also become closer to the actual situations faced by managers when they are making ordering policies.

In this paper, we study the loss-averse retailer's optimal ordering policy for perishable product with customer returns. The remainder of this paper is organized as follows. In Section 2, we described the problem and assumptions. Section 3 studies the loss-averse retailer's optimal ordering policies for perishable product with customer returns. The impacts of parameters on the loss-averse retailer's optimal ordering policies are discussed in Section 4. Finally, we conclude our findings and highlight possible future work in Section 5 .

\section{Problem Description and Assumptions}

In this paper, we consider a retailer who has the tendency of loss aversion when making decisions. He sells single-cycle products and commits that products can be returned with full refund during the sales period. At the end of the sales period, the return products and the remaining stocks are sold at a lower price than wholesale price and not allowed to return. The demand of these return products is independent on the demand of the normal products. We can statistically obtain from the historical data that the proportion of the customer returns, and assume as $k$, where $0 \leq k<1$. We introduce the linear piecewise loss aversion utility function to characterize the tendency of the retailer's decision making; that is,

$$
U(W)= \begin{cases}\pi W, & \text { if } W \geq W_{0}, \\ \lambda W, & \text { if } W<W_{0} .\end{cases}
$$

$\lambda$ is the coefficient of the loss aversion, and $\lambda>1 . W_{0}$ is the initial wealth of the decision maker. Without loss of generality, we set $W_{0}=0$, which means the initial wealth of the decision maker is zero.

We assume that the loss-averse retailer's order quantity is $Q$. The customers' demand for the normal products is $D$, which is a continuous, differentiable, and invertible random variable with probability density function (PDF) $f(x)$ and cumulative distribution function (CDF) $F(x) . F(x)$ is nonnegative, strictly increasing and $F(0)=0 . \bar{F}(x)=1-F(x)$ denotes the tail distribution. The unit retail price is $p$ and the unit wholesale price is $w, p>w$. The unit selling price of the return products is $v, v<w$. The shortage cost of per unit is $s$. We assume that $(p-v)(1-k) \geq w-v$. Otherwise, the loss-averse retailer will not want to sell products.

\section{Modeling and Solutions}

With stochastic demand and customer returns, the lossaverse retailer may face two situations: the actual demand is greater than the order quantity or the actual demand is less than the order quantity. Then we get that the retailer's profit, denoted by $\pi(x, Q)$, is

$$
\begin{aligned}
& \pi(x, Q) \\
& =\left\{\begin{array}{rlrl}
\pi_{-}(x, Q)= & p(1-k) x+v(Q-x) & & \\
& +v k x-w Q, & & x \leq Q, \\
\pi_{+}(x, Q)= & p(1-k) x+k Q v & & \\
& -s(x-Q)-w Q, & x>Q .
\end{array}\right.
\end{aligned}
$$

Set $\pi_{-}(x, Q)=0$; we get that when $x \leq Q$, the breakeven point is $q_{1}(Q)=(w-v) Q /(p-v)(1-k)$. That is, when the actual demand is less than the breakeven point $x<q_{1}(Q)$, the loss-averse retailer's profits are negative; when the actual demand is greater than the breakeven point $q_{1}(Q)<x<$ $Q$, the loss-averse retailer's profits are positive. Similarly, set $\pi_{+}(x, Q)=0$; we can see that when $x>Q$, the breakeven point is $q_{2}(Q)=[(p-v)(1-k)-(w-v)+s] Q / s$. That is, when $Q<x<q_{2}(Q)$, the retailer's profits are positive; when $x \geq q_{2}(Q)$, the loss-averse retailer's profits are negative.

Then, we get that the loss-averse retailer's expected utility function, denoted by $E[U(\pi(x, Q))]$, is

$$
\begin{aligned}
E[U(\pi(x, Q))]= & (\lambda-1) \\
& \times \int_{0}^{q_{1}(Q)}[(p-v)(1-k) x \\
& \quad-(w-x) Q] f(x) d x \\
& +E[\pi(x, Q)]+(\lambda-1) \\
& \times \int_{q_{2}(Q)}^{+\infty}[(p-v)(1-k) Q-(w-v) Q \\
& +s Q-s x] f(x) d x .
\end{aligned}
$$

As to the loss-averse retailer's optimal order quantity, the following proposition is obtained. 
Proposition 1. The loss-averse retailer's expected utility function with customer returns is concave in $Q$. There is a unique optimal order quantity that maximizes the loss-averse retailer's expected utility with customer returns and satisfies the following condition:

$$
\begin{aligned}
& {[(p-v)(1-k)-(w-v)+s]} \\
& \quad \times\left[(\lambda-1) \bar{F}\left(q_{2}\left(Q^{*}\right)\right)+\bar{F}\left(Q^{*}\right)\right] \\
& \quad-(w-v)\left[F\left(Q^{*}\right)+(\lambda-1) F\left(q_{1}\left(Q^{*}\right)\right)\right]=0 .
\end{aligned}
$$

Proof. Taking into consideration the retailer's breakeven point $q_{1}(Q)=(w-v) Q /(p-v)(1-k)$ and $q_{2}(Q)=[(p-v)(1-$ $k)-(w-v)+s] / Q$, from $(3)$ we get that $d E[U(\pi(x, Q))] / d Q=$ $-(w-v)\left[F(Q)+(\lambda-1) F\left(q_{1}(Q)\right)\right]+[(p-v)(1-k)-(w-$ $v)+s]\left[(\lambda-1) \bar{F}\left(q_{2}(Q)\right)+\bar{F}(Q)\right]$ and $d^{2} E[U(\pi(x, Q))] / d Q^{2}=$ $-(\lambda-1)[(p-v)(1-k)-(w-v)+s] f\left[q_{2}(Q)\right]\left(d q_{2}(Q) / d Q\right)-$ $(\lambda-1)(w-v) f\left[q_{1}(Q)\right]\left(d q_{1}(Q) / d Q\right)-[(p-v)(1-k)+$ $s] f(Q)$. Since $d q_{1}(Q) / d Q>0$ and $d q_{2}(Q) / d Q>0$, then $d^{2} E[U(\pi(x, Q))] / d Q^{2}<0$. That is, the expected utility function $E[U(\pi(x, Q))]$ is a concave function in $Q$.

Let $d E[U(\pi(x, Q))] / d Q=0$; we can get the stationary point $Q^{*}$, which satisfies the following formula: $[(p-v)(1-$ $k)-(w-v)+s]\left[(\lambda-1) \bar{F}\left(q_{2}\left(Q^{*}\right)\right)+\bar{F}\left(Q^{*}\right)\right]-(w-$ v) $\left[F\left(Q^{*}\right)+(\lambda-1) F\left(q_{1}\left(Q^{*}\right)\right)\right]=0$. Since $F(x)$ is continuous, reversible in the interval, and $d E[U(\pi(x, 0))] / d Q>0$, $d E[U(\pi(x, \sup I))] / d Q<0$, so the stationary point $Q^{*}$ is the only order quantity corresponding to the maximum expected utility. This completes the proof.

When $\lambda=1$, the loss-averse retailer becomes the risk neutral. Based on Proposition 1, we can derive the following corollary.

Corollary 2. (1) If $[(p-v)(1-k)-(w-v)+s] \bar{F}\left[q_{2}\left(Q_{0}^{*}\right)\right]>$ $(w-v) F\left[q_{1}\left(Q_{0}^{*}\right)\right]$, then $Q_{0}^{*}<Q^{*}$.

(2) If $[(p-v)(1-k)-(w-v)+s] \bar{F}\left[q_{2}\left(Q_{0}^{*}\right)\right]<(w-$ v) $F\left[q_{1}\left(Q_{0}^{*}\right)\right]$, then $Q_{0}^{*}>Q^{*}$.

(3) If $[(p-v)(1-k)-(w-v)+s] \bar{F}\left[q_{2}\left(Q_{0}^{*}\right)\right]=(w-$ v) $F\left[q_{1}\left(Q_{0}^{*}\right)\right]$, then $Q_{0}^{*}=Q^{*}$.

From Corollary 2, we can see that the relations between the loss-averse retailer's optimal order quantities with customer returns and the risk-neutral retailer's optimal order quantity with customer returns depend on the marginal holding cost and the marginal shortage cost.

As to the effect of customer returns, we can derive the following corollary from Proposition 1.

Corollary 3. The loss-averse retailer's optimal order quantities with customer returns are lower than the case without customer returns.

Corollary 3 means that customer returns will reduce the loss-averse retailer's optimal order quantities with customer returns.

\section{Discussion}

In this section, we will discuss the effect of relevant parameters on the loss-averse retailer's optimal order policies with customer returns. As to the effect of the coefficient of loss aversion on the loss-averse retailer's optimal order quantity, the following proposition is obtained.

Proposition 4. (1) if $[(p-v)(1-k)-(w-v)+s] \bar{F}\left[q_{2}\left(Q^{*}\right)\right]>$ $(w-v) F\left[q_{1}\left(Q^{*}\right)\right], Q^{*}$ is increasing in $\lambda$; (2) if $[(p-v)(1-$ $k)-(w-v)+s] \bar{F}\left[q_{2}\left(Q^{*}\right)\right]=(w-v) F\left[q_{1}\left(Q^{*}\right)\right], Q^{*}$ is constant in $\lambda$; (3) if $[(p-v)(1-k)-(w-v)+s] \bar{F}\left[q_{2}\left(Q^{*}\right)\right]>(w-$ v) $F\left[q_{1}\left(Q^{*}\right)\right], Q^{*}$ is decreasing in $\lambda$.

Proof. For Proposition 1, we can get that

$$
\begin{aligned}
& \frac{d Q^{*}}{d \lambda} \\
& =\frac{d^{2} E\left[U\left(\pi\left(x, Q^{*}\right)\right)\right] / d Q^{*} d \lambda}{-d^{2} E\left[U\left(\pi\left(x, Q^{*}\right)\right)\right] / d Q^{* 2}} \\
& =\left(-(w-v) F\left[q_{1}\left(Q^{*}\right)\right]+[(p-v)(1-k)-(w-v)+s]\right. \\
& \left.\quad \times \bar{F}\left[q_{2}\left(Q^{*}\right)\right]\right)\left(\frac{-d^{2} E\left[U\left(\pi\left(x, Q^{*}\right)\right)\right]}{d Q^{* 2}}\right)^{-1} .
\end{aligned}
$$

So, if $[(p-v)(1-k)-(w-v)+s] \bar{F}\left[q_{2}\left(Q^{*}\right)\right]>(w-$ $v) F\left[q_{1}\left(Q^{*}\right)\right], d Q^{*} / d \lambda>0$; that is, $Q^{*}$ is increasing in $\lambda$; if $[(p-v)(1-k)-(w-v)+s] \bar{F}\left[q_{2}\left(Q^{*}\right)\right]=(w-v) F\left[q_{1}\left(Q^{*}\right)\right]$, $d Q^{*} / d \lambda=0$; that is, $Q^{*}$ is constant in $\lambda$; if $[(p-v)(1-k)-$ $(w-v)+s] \bar{F}\left[q_{2}\left(Q^{*}\right)\right]>(w-v) F\left[q_{1}\left(Q^{*}\right)\right], d Q^{*} / d \lambda<0$; that is, $Q^{*}$ is decreasing in $\lambda$. This completes the proof.

This proposition means that the loss-averse retailer's optimal order quantities with customer returns may be increasing (constant or decreasing) in the coefficient of loss aversion; it depends on the cost parameters.

As to the effect of shortage cost on the loss-averse retailer's optimal order policies with customer returns, the following proposition is obtained.

Proposition 5. $Q^{*}$ is increasing in s.

Proof. For Proposition 1, we obtain that

$$
\begin{aligned}
& \frac{d Q^{*}}{d s} \\
& =\frac{d^{2} E\left[U\left(\pi\left(x, Q^{*}\right)\right)\right] / d Q^{*} d s}{-d^{2} E\left[U\left(\pi\left(x, Q^{*}\right)\right)\right] / d Q^{* 2}} \\
& =\left((\lambda-1) \bar{F}\left[q_{2}\left(Q^{*}\right)\right]+(\lambda-1) f\left[q_{2}\left(Q^{*}\right)\right]\right. \\
& \left.\quad \times \frac{(p-v)(1-k)-(w-v)}{s}\right) \\
& \quad \times\left(\frac{-d^{2} E\left[U\left(\pi\left(x, Q^{* 2}\right)\right)\right]}{d Q^{* 2}}\right)^{-1}>0 .
\end{aligned}
$$

That is, $Q^{*}$ is increasing in $s$. This completes the proof. 
From this proposition, we know that the loss-averse retailer's optimal order quantities with customer returns are the increasing function of the shortage cost.

As to the effect the proportion of customer returns, we can use a similar method of proof as Proposition 5 and get the following proposition.

\section{Proposition 6. $Q^{*}$ is decreasing in $k$.}

This proposition shows that the loss-averse retailer's optimal order quantities with customer returns are the decreasing function of the proportion of customer returns.

\section{Conclusions and Future Research}

In this paper, we consider the loss-averse retailer's optimal order policies with customer returns. The main conclusions are as follows.

(1) There exists a unique optimal order quantity that maximizes the loss-averse retailer's expected utility with customer returns. Customer returns will reduce the loss-averse retailer's optimal order quantities with customer returns.

(2) The loss-averse retailer's optimal order quantities with customer returns are higher (equal or lower) than the risk-neutral retailer's optimal order quantity with customer returns, and the relations depend on relationship of the marginal holding cost and the marginal shortage cost.

(3) The loss-averse retailer's optimal order quantities with customer returns may be increasing (constant or decreasing) in the coefficient of loss aversion. The relationship depends on the cost parameters. The loss-averse retailer's optimal order quantities with customer returns are increasing in the shortage cost and decreasing in the proportion of customer returns.

Our paper assumes that the demands for normal products and return products are independent with each other, which may have a certain relationship between them. Further research may investigate the cases when the two kind products are correlative. This paper is from the retailer's view, further study can extend to the view of supply chain. Customer return is investigated in this paper to hedge the demand risk, and other supply chain risk hedge tools, such as option contracts $[1,3]$, transshipment [14], can be taken into consideration in the future. Another natural extension of our work is to consider more general supply chains, such as multiple supplier and/or multiple retailer models $[15,16]$.

\section{Conflict of Interests}

The authors declare that there is no conflict of interests with the named companies regarding the publication of this paper.

\section{Acknowledgments}

The authors thank the editor and the referees for carefully reading the paper. The first author (Xu Chen) is supported by National Natural Science Foundation of China (nos. 71432003, 71272128), National Soft Science Research Program (no. 2013GXS4D145), and Program for New Century Excellent Talents in University (no. NCET-12-0087). The second author (Qian Zhou) is supported by Specialized Research Fund for the Doctoral Program of Higher Education (no. 20130185110006) and Youth Foundation for Humanities and Social Sciences of Ministry of Education of China (no. 11YJC630022).

\section{References}

[1] X. Chen and Z.-J. Shen, "An analysis of a supply chain with options contracts and service requirements," IIE Transactions, vol. 44, no. 10, pp. 805-819, 2012.

[2] B. Shen, P.-S. Chow, and T.-M. Choi, "Supply chain contracts in fashion department stores: coordination and risk analysis," Mathematical Problems in Engineering, vol. 2014, Article ID 954235, 10 pages, 2014.

[3] X. Chen, G. Hao, and L. Li, "Channel coordination with a lossaverse retailer and option contracts," International Journal of Production Economics, vol. 150, pp. 52-57, 2014.

[4] T. Feng, L. R. Keller, and X. Zheng, "Decision making in the newsvendor problem: a cross-national laboratory study," Omega, vol. 39, no. 1, pp. 41-50, 2011.

[5] T. H. Ho and J. Zhang, "Designing pricing contracts for boundedly rational customers: does the framing of the fixed fee matter?” Management Science, vol. 54, no. 4, pp. 686-700, 2008.

[6] J. Wu, S. Wang, X. Chao, C. T. Ng, and T. C. E. Cheng, "Impact of risk aversion on optimal decisions in supply contracts," International Journal of Production Economics, vol. 128, no. 2, pp. 569576, 2010.

[7] A. A. Tsay, "Risk sensitivity in distribution channel partnerships: implications for manufacturer return policies," Journal of Retailing, vol. 78, no. 2, pp. 147-160, 2002.

[8] J. Chen and P. C. Bell, "Coordinating a decentralized supply chain with customer returns and price-dependent stochastic demand using a buyback policy," European Journal of Operational Research, vol. 212, no. 2, pp. 293-300, 2011.

[9] J. Chen and P. C. Bell, "The impact of customer returns on pricing and order decisions," European Journal of Operational Research, vol. 195, no. 1, pp. 280-295, 2009.

[10] D. Kahneman and A. Tversky, "Prospect theory: an analysis of decision under risk," Econometrica, vol. 47, no. 2, pp. 263-292, 1979.

[11] M. E. Schweitzer and G. P. Cachon, "Decision bias in the newsvendor problem with a known demand distribution: experimental evidence," Management Science, vol. 46, no. 3, pp. 404420, 2000.

[12] C. X. Wang and S. Webster, "The loss-averse newsvendor problem," Omega, vol. 37, no. 1, pp. 93-105, 2009.

[13] Q. Li, Z. Liu, and Y. He, "Impact of risk aversion on price and quality decisions under demand uncertainty via the CARA utility function," Mathematical Problems in Engineering, vol. 2014, Article ID 490121, 15 pages, 2014.

[14] X. Chen, G. Hao, X. Li, and K. F. C. Yiu, "The impact of demand variability and transshipment on vendor's distribution policies under vendor managed inventory strategy," International Journal of Production Economics, vol. 139, no. 1, pp. 42-48, 2012. 
[15] X. Chen, A. H. Tai, and Y. Yang, "Optimal production and pricing policies in a combined make-to-order/make-to-stock system," International Journal of Production Research, 2014.

[16] X. Chen, L. Li, and M. Zhou, "Manufacturer's pricing strategy for supply chain with warranty period-dependent demand," Omega, vol. 40, no. 6, pp. 807-816, 2012. 


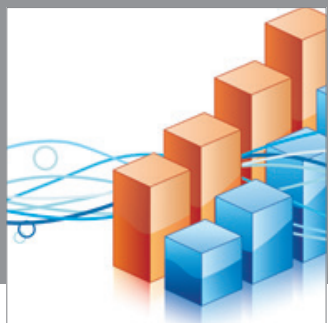

Advances in

Operations Research

mansans

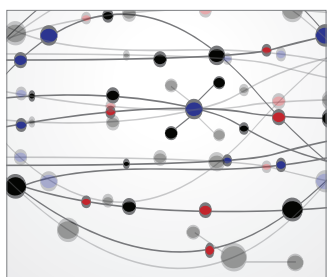

The Scientific World Journal
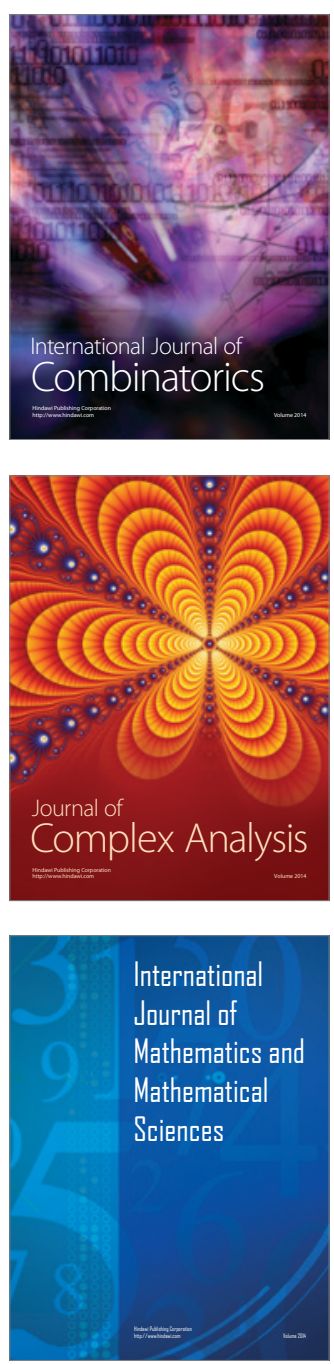
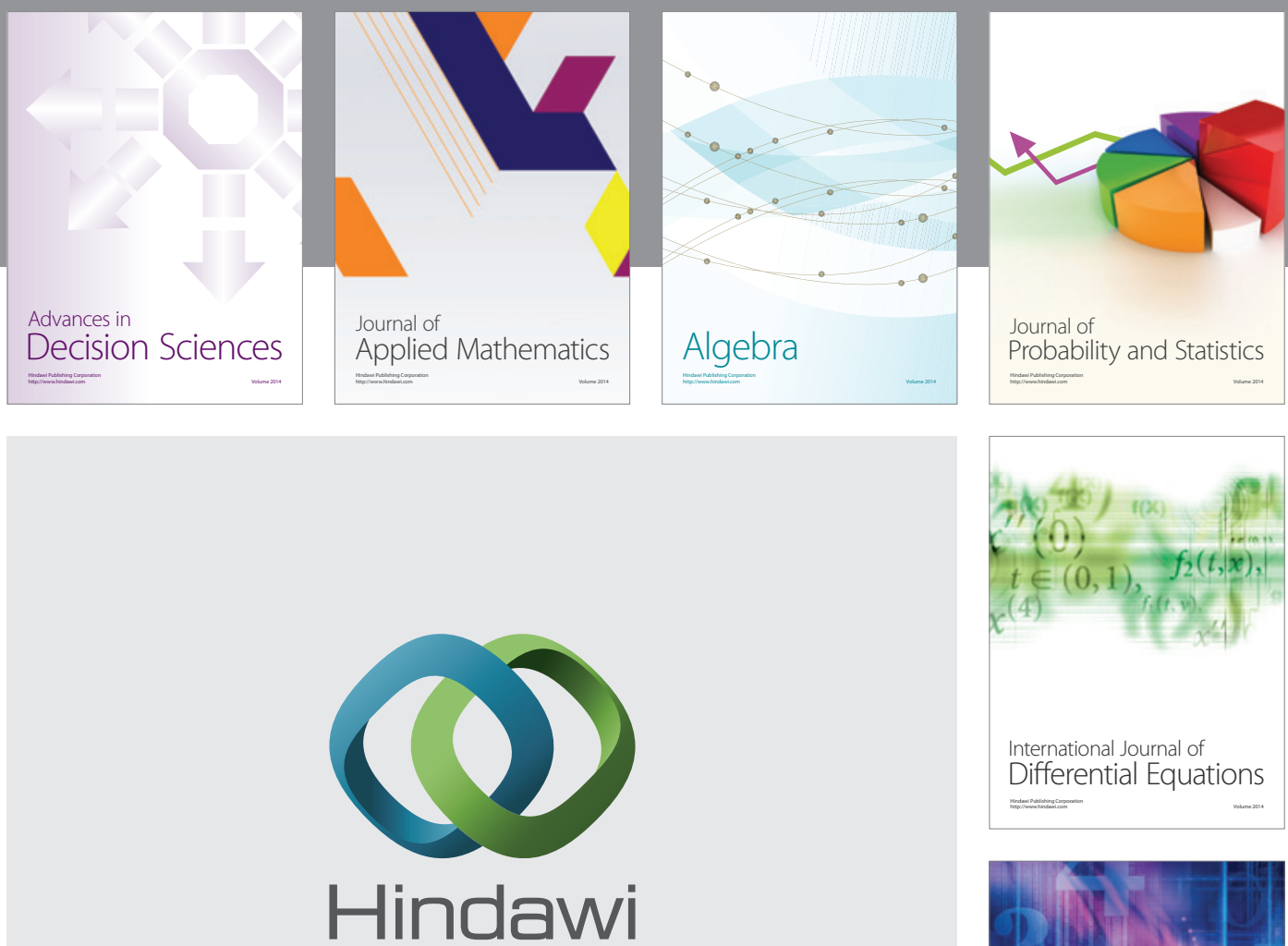

Submit your manuscripts at http://www.hindawi.com
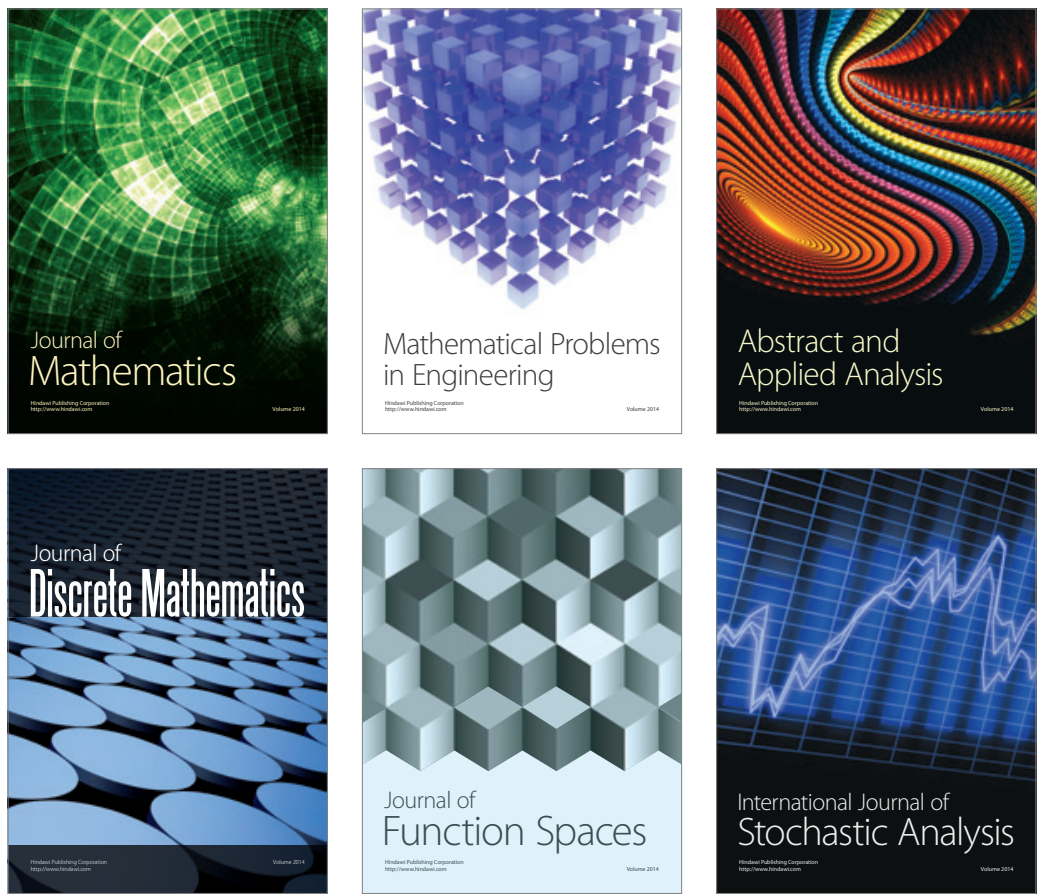

Journal of

Function Spaces

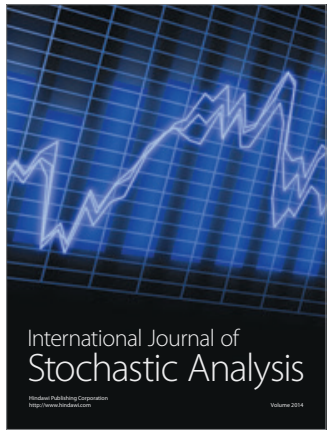

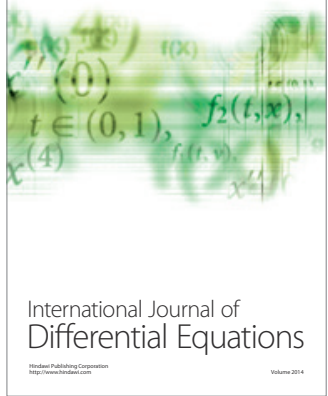
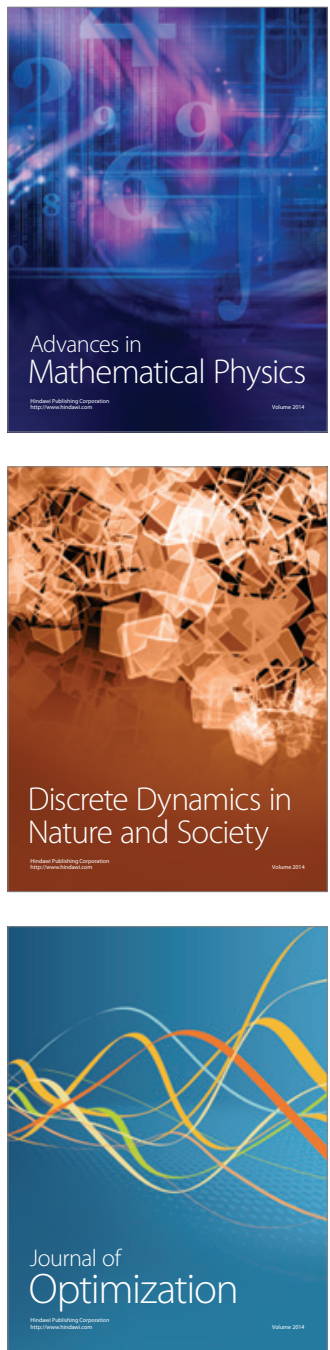